\title{
Efficacy of Static and Intermittent Gravity Inverted Therapy Techniques in Improvement of Motor Apraxia and Cognitive Abilities in Autism Spectrum Disorder (ASD)
}

\author{
Ahmed M. Azam \\ Department of Physiotherapy for Developmental Disturbance and Pediatric Surgery, Faculty of Physical Therapy, \\ Cairo University, Giza, Egypt \\ Email: prof.ahmedazzam@yahoo.com
}

How to cite this paper: Azam, A.M. (2018) Efficacy of Static and Intermittent Gravity Inverted Therapy Techniques in Improvement of Motor Apraxia and Cognitive Abilities in Autism Spectrum Disorder (ASD). World Journal of Neuroscience, $\mathbf{8}$, 314-331.

https://doi.org/10.4236/wjns.2018.82025

Received: April 9, 2018

Accepted: May 22, 2018

Published: May 25, 2018

Copyright $\odot 2018$ by author and Scientific Research Publishing Inc. This work is licensed under the Creative Commons Attribution International License (CC BY 4.0).

http://creativecommons.org/licenses/by/4.0/

(c) (i) Open Access

\begin{abstract}
This work was carried out to investigate the efficacy of static and intermittent gravity inverted therapy techniques in improvement of motor apraxia and cognitive abilities in Autism Spectrum Disorder (ASD). 30 children were randomly joined in this study into two groups; Group A (sensory integration therapy approach plus static and intermittent inversion therapy techniques) and Group B (sensory integration therapy approach only). Block design test was used to locate and follow constructional apraxia, computerized information processing speed test to locate and follow cognitive processing and grooved pegboard test was used to locate and follow fine motor skills. The variance between pre- and post-treatment results was highly significant in the study group in all variables. By comparison of the two groups in constructional apraxia variables test at post-treatment, there was a highly representative elevation in favour to study groups $(\mathrm{p}<0.05)$. By comparison of the two groups in cognitive processing variable at post-treatment, there was a highly representative elevation in favour to study group $(\mathrm{p}<0.05)$. By comparison of the two groups in fine motor skills variable at post-treatment, there was a highly representative elevation in favor to study group $(\mathrm{p}<0.05)$. According to the outcomes of this study, it can be terminated that the sensory integration therapy approach plus static and intermittent inversion therapy techniques can be recommended in improvement constructional apraxia and cognitive processing abilities in autism spectrum disorder (ASD) children.
\end{abstract}

\section{Keywords}

Inversion Therapy, Motor Apraxia, Autism Spectrum Disorder (ASD) 
Children

\section{Introduction}

The gravity is a friend to normal alignment posture but produce a harmful impact on malalignment posture leading to weak antigravity muscles as back and abdominal muscles leading to poor posture and muscle disturbance. Inversion therapy can manage negative impact of gravity via producing elongation of the spine, relieve pressure on the ligament and nerve root and increase body balance [1]. The spine has been got free from gravity stress, widening of the vertebral space with lengthening of the body [2].

Zero gravity position is considered the lowest gravitational force act on the spine and body. The different inversion therapy inclinations put the posture in zero gravity position which modulate the effects of gravity and allow for proper circulation, spine and extremities proper alignment. This also named weightlessness position in which the level of feet is higher than the level of the heart [3]. The weightlessness position takes the forces of gravity away from the spine produce relaxation of the spine and extremities muscles [4]. In inverted head posture there is freshly oxygenated blood efficiently directed toward active areas of the brain [5] leading to increasing of the cells exchange of nutrients and waste products with the capillaries leading to increase the availability of oxygen and glucose which are considered the most vital substrates for the brain [6].

There are two types of inversion therapy techniques. The first one is called static inversion which is aiming for stretching the spinal column releasing the nerve root compression. This technique require specific tilting angle for a few minutes. The second technique is the intermittent inversion which produced intermittent rocking motion between upright and inverted position. The cycle of intermittent technique lasts for 20 - 30 seconds aiming for improving of freshly oxygenated blood to brain areas [7].

ASD children were suffering from flexion attitude of posture with lack of reciprocal movement between upper and lower limbs, involuntary stereotyped movement, dyskinesia, language disorder, slow, lack of reaction, repetitive impulsive movement and slow tiptoes walking [8]. There is also apraxia and balance impairment [9]. Motor skills is considered the essential core for learning different skills such as social, communication and perceptual skills which are in a bad needed to be developed in ASD [10].

The direct benefits of the inversion therapy are improving of the lymphatic system and increase of venous return produce facilitation of the autonomic nervous system and its baroreceptors increasing oxygen flow to the brain centers and remove of the waste products into the venous system, inhibit the spasmed and tight muscles in scoliosis, spinal muscles spasm leading to improve of original body posture and decreasing of recovery time [11]. Other mechanical bene- 
fits of inversion therapy include relaxation of the ligamentum flavum, widening of the facet and intervertebral disc spaces [12], modulation of intervertebral disc pressure, correction of lumbar curve disorder, stretching of the paraspinal muscles and tensing of the post, and longitudinal ligament producing vertebral support [13] [14].

\section{Materials and Methods}

\subsection{Demography}

30 autistic spectrum disorder (ASD) children from both sexes were randomly selected from schools of intellectual education, aged 8 to 12 years at the time of recruitment because the children in this age who can understand the research work principles and rules were entered in the study. Body weight, height and level of ambulation via gross motor function measure were recorded for each subject. The inclusive criteria were (lack of reaction, flexion bad posture, slow walking, skills apraxia, balance impairment and lack of cognitive abilities). Excluded criteria were (spinal instability, blood disease, laxity of ligaments, ocular problems, children who had previous heart, spine and brain surgery).

\subsection{Sample Collection}

\section{Children were randomized to:}

Group A (experimental group): It contained 15 autistic children. They received sensory integration therapy approach plus static and intermittent inversion therapy technique.

Group B (control): It contained 15 autistic children receiving sensory integration therapy approach only. Informed consent was obtained from all children in both groups.

ASD is a genetic mutation disorder suffering from sensory integration disorder in cerebellum and basal ganglion which is the step before acquisition of new skills so there are impaired of gross, fine, $\mathrm{ADL}$, communication and social skills. Motor dysfunction management in ASD is a key and neck bottle that should concern with it to provide an efficient rehabilitation program to improve primary behaviour problems as cognitive, social and communicative skills.

\subsection{Outcome Measurements}

1) Constructional apraxia test: By using block design test, the child was asked to perform a building tower task or copying a design.

- The time was calculated in seconds. The maximum time for performance was up to 180 seconds whether or not the task completed.

- The accuracy of performance was calculated by counting the numbers of trials correctly constructed [15].

2) Cognitive processing test: By using computerized information processing speed test which is the reaction time between information received and the appropriate response. Cognitive skill played an essential role in learning and expe- 
rience process.

Low reaction time leaded to poor motor planning and every stage of motor learning.

- Simple reaction time: The child pressed a specific key in response to see a letter on the computer screen (motor speed).

- Choice reaction time: The child was given one of two words and asked to choose by pressing on the key (decision making) [15].

3) Fine motor skills test: By using grooved pegboard test, the children performance efficiency was measured via calculating the time of performing pegs in the appropriate groove.

\subsection{Intervention}

The way to improve learning process in ASD is the facilitation of information processing which improved the CNS neural plasticity mechanism leading to increase of new synaptic connections and reorganizations besides new neural circuits and neurogenesis.

\section{For both groups before and after treatment:}

Physical problems of ASD:

1) Visually incoordination.

2) Undeveloped muscles lead to reduced muscle tone.

3) Impaired sensory processing leaded to abnormal response to sensory incoming situation:

a) arousal dysfunction;

b) problem in interaction with others;

c) delayed learning of motor skills;

d) motor abnormalities [16] [17] [18].

4) Poor proprioception leaded to:

a) poor motor planning;

b) poor imitation skills;

c) poor postural position [19] [20] [21].

5) Delaying of fine, gross motor skills.

6) Delayed ADL activities due to severe sensory skills dysfunction and tolerance affect on their interactions with everyday life [22].

7) Toe walking.

8) Poor coordination.

9) Poor balance.

10) Functionally dependent.

\section{Goals of sensory integration therapy:}

1) To improve the delayed motor abilities via facilitation of postural reaction components in static and dynamic situation.

2) To enhance independency via facilitation of ADL activities.

3) To enhance the acquisition of functional, fine motor, gross motor, social and communicating skills via reduction of reaction time required for performing 
a task as hand function training.

4) To improve motor planning and organization training via teaching tools.

5) To train normal movement pattern in different situation.

6) To improve sensory motor integration training.

7) To correct posture alignment [23].

Sensory integration therapy concern with improvement of the fine and gross motor development, visual motor integration, balance and postural control, tactile, vestibular, proprioceptive sensations, coordination and motor planning [18].

The role of SIT approach for autistic children include the controlling of sensory feedback from vestibular sensations and muscles, joints and skin sensations to help child to readjust the specific reactions via enable them to perform correctly interpretation of sensory informations [24]. Sensory motor integration therapy focused on interactions between sensory process, neural mechanism and behaviour. It is indicated in cerebral palsy, ASD and attention deficient syndrome [25] [26] [27].

\section{Proprioceptive training:}

- Weight bearing training as hand weight bearing, positioning and reciprocal movement of upper limb.

- Dynamic approximation for all joints.

- Pushing and pulling a weighted ball.

- Dressing of weighted clothes.

- Holding a hide subject from sand or beans.

\section{Cortical sense training:}

- Different material characteristics to stimulate stereognosis skills as different object size, shape, weight and texture of materials.

The sensations types include the 1st proprioception sense comes from joint and muscle for detecting position and movement which is followed by motor response, the 2nd surface sense touch, pressure, heat, pain which localized in sensory cortex area $3,1,2$. The 3 rd one is the cortical sense as stereo gnosis in which child has the ability to differentiate between shape, size and texture of material [28] [29].

\section{Extroceptive training:}

- Pressuring, brushing and scrubbing extremities and back.

- Touching stimulation via books, sands, beans, rice, drawing different figures by the hand, rolling on different textures surfaces, blowing toys, taste stimulation, smell, visual and hearing stimulation.

- Different surface heat (normal, warm, hot, cold).

- Different surface touch (rough, smooth, rubbery, slippery, crude and wool). In the treatment of tactile impairment in ASD the therapist should detect sensitivity of the child sensation either hypersensitive to tactile stimulation or hyposensitive. Some autistic children have hypersensitivity in some tactile stimulants and hyposensitive in the other. So in the following methods we can control 
the stimulants according to the sensitivity to correct reaction movement.

\section{Vestibular training:}

- Supine, prone, sitting, quadruped, kneeling, half kneeling and standing with disturbance.

- Adjusting of BOS and COG and eye closure for stimulation of equilibrium and protective reaction.

- Swinging therapy training.

- Standing on one foot, walking on balance board, swinging on balance board, swinging training, walking on one line, side walking and by pass walking.

In the treatment of proprioceptive impairment, the child suffered from postural imbalance, repeated falling, inability to perform ADL activities, inability to carry heavy object, attached weight on hand, ankle and back and weight bearing and approximation training [26].

The experimental group (Group A) received static and intermittent inversion therapy approach as following:

Inversion therapy is a form of mechanical treatment in which the child is strapped at both ankles in inversion tables. The children were gradually tilted to a head down position in static and intermittent inversion therapy. Inversion therapy techniques are indicated in patients with motor apraxia and mild cognitive skills impairments [30].

\section{There are different inversion therapy tools as:}

1) Head backward over physio-ball.

2) Inversion table.

3) Inversion chair.

4) Slope over the edge of the bed or wedge.

5) On the lap gentle backward over your knees.

6) Hold the child upside-down.

Gravity and position changes to spinal and extremity input and pressurization, in addition to vestibular indicators of body placement and cortical modulation, may produce vital adjustments in the motor planning of skill performance and cognitive abilities. Our environment is active due to resistance by the gravity which equal to amount of body weight. Bird environment is passive. The active environment produced compressive forces that stored in the joints. Gravity is the cause of many compressive negative effects on the body as sagging organs, compressed joints and discs, varicose vein, baggy eyes, decreased height of half inch every 20 years and long run effect of pulling the body downward. The key of treatment of several diseases was counteracting compressive force produced by the gravity via a necessary, vital pro-gravity posture which is the inversion posture which is the valve for relieving the negative effects of gravity on the body.

\section{Indications of inversion therapy:}

1) Movement disorder (motor apraxia).

2) Mild cognitively impairment. 


\section{Contra-indication:}

Someone had blood disease, epileptic seizure, neck and head, heart and chest surgery, ocular problems, increased intracranial pressure, spinal instability, joint hypermobility, uncooperative and semiconscious patients [30].

Precautions: must be followed to prevent and protect children from any harm.

1) Invert slowly then return slowly and progress slowly.

2) Be careful inversion therapy did not like other exercise therapy. It produced stretching and manipulation at the same time.

3) Invert only to a comfortable angle. Full inversion to 90 degree isn't required to all patients.

4) Invert for a short period of time (static $1-3$ minutes, intermittent $5-10$ minutes per session.

5) Heart rate, respiratory rate, pulse rate and breath hold should be monitored before and after the session.

6) We stay in horizontal posture $8 \mathrm{H}$ and $16 \mathrm{H}$ in upright posture. We should save some time to pro-gravity posture (inversion posture).

\section{Types of inversion therapy:}

1) Static: Posture maintained for 1 - 3 minutes in specific comfortable angle (between 20 - 30 degree for the 1st 4 weeks then from 30 - 45 degree for the 2 nd 4 weeks and from 45 - 60 degree for last 4 weeks). It produced mild stretching and manipulation to muscles, ligament and tendons in addition to vestibular system stimulation and proprioceptive stimulation for sensory awareness.

2) Intermittent: Rocking, gentle swing motion between upright position and inverted position with duration cycle of 20 - 30 seconds for each cycle for 5 - 10 minutes. It started with 1 - 2 minutes with lowest degree of inversion (between 20 - 30 degree for the 1st 4 weeks then from 30 - 45 degree for the 2 nd 4 weeks and from 45 - 60 degree for last 4 weeks). It improved fresh oxygenated blood to the brain areas due to increased blood circulation [7].

\subsection{Statistical Analysis}

SPSS statistical package was used to calculate $\mathrm{p}$ value via dependent and independent $\mathrm{t}$ test. Statistical significance was determined at $\mathrm{p}<0.05$.

\section{Result}

\subsection{Patients' Characteristics}

The patient's characteristics were displayed in Table 1 . There were 24 boys $(80 \%)$ and 6 girls (20\%). There was no representative difference in all children in regarding age $(\mathrm{p}=0.8829)$, in regards to sex $(\mathrm{p}=1.0000)$.

\subsection{Changes in Constructional Apraxia Variable}

Mean test scores and SD for the two groups are displayed in Table 2. The 
Table 1. Patients charactaristics.

\begin{tabular}{cccc}
\hline Variables & Study group N $=15$ & Control group N $=15$ & p-value \\
\hline Age & $10.27 \pm 1.28$ & $10.33 \pm 1.18$ & 0.8829 \\
Sex N \% & & & \\
Boys & $12(80 \%)$ & $12(80 \%)$ & 1.0000 \\
Girls & $3(20 \%)$ & $3(20 \%)$ & \\
\hline
\end{tabular}

Table 2. The average test of Constructional apraxia variable in both groups.

\begin{tabular}{cccc}
\hline $\begin{array}{c}\text { Building tower } \\
\text { performance variable }\end{array}$ & $\begin{array}{c}\text { Study group } \\
\text { Mean } \pm \text { SD }\end{array}$ & $\begin{array}{c}\text { Control group } \\
\text { Mean } \pm \text { SD }\end{array}$ & $\begin{array}{c}\text { p-value } \\
\text { (within groups) }\end{array}$ \\
\hline Pre-treatment & $53.00 \pm 2.07$ & $52.27 \pm 2.96$ & 0.4386 \\
Post-treatment & $51.53 \pm 1.81$ & $52.20 \pm 2.34$ & 0.2292 \\
Improvement \% & $2.77 \%$ & $0.13 \%$ & 0.0022 \\
p-value (within groups) & 0.0001 & 0.8550 & \\
\hline
\end{tabular}

mean record of Constructional apraxia variable in both groups (assessed by building tower performance) at baseline measurement (pre-treatment and post treatment) were insignificant ( $p>0.05)$. Besides study group had a highly statistical progress in building tower performance post-treatment $(\mathrm{p}<0.05)$ in contrast there is no statistical progress in the treatment group. The average progress of building tower performance variable tended to be highly represented of the study group $(53.00 \pm 2.071$ versus $51.53 \pm 1.81 \mathrm{p}=0.0001)$ while insignificant result in the control group $(52.27 \pm 2.96$ versus $52.20 \pm 2.34, \mathrm{p}=0.8550)$. The proportion of progress of eye building tower performance was $(2.77 \%)$ in the study group while it was $(0.13 \%)$ in control group.

\subsection{Changes in Constructional Apraxia Variable}

Mean test scores and SD for the two groups are displayed in (Table 3). The mean record of Constructional apraxia variable in both groups (assessed by copying design variable) at baseline measurement (pre-treatment and post treatment) were insignificant ( $p>0.05)$. Besides study group had a highly statistical progress in copying design variable post-treatment $(\mathrm{p}<0.05)$, in contrast there is no statistical progress in the treatment group. The average progress of copying design variable tended to be highly represented of the study group (22.80 \pm 2.651 versus $21.47 \pm 2.42 \mathrm{p}=0.0001$ ) while insignificant result in the control group $(23.20 \pm 2.14$ versus $23.07 \pm 2.05 \mathrm{p}=0.3343)$. The proportion of progress of copying design variable was $5.83 \%$ in the study group while it was $0.6 \%$ in control group.

\subsection{Changes in Cognitive Processing Variable}

Mean test scores and SD for the two groups are displayed in Table 4. The mean record of cognitive processing variable in both groups (assessed by motor speed test) at baseline measurement (pre-treatment and post treatment) were 
Table 3. The average test of Constructional apraxia variable in both groups.

\begin{tabular}{cccc}
\hline $\begin{array}{c}\text { Performance of copying } \\
\text { design variable }\end{array}$ & $\begin{array}{c}\text { Study group } \\
\text { Mean } \pm \text { SD }\end{array}$ & $\begin{array}{c}\text { Control group } \\
\text { Mean } \pm \text { SD }\end{array}$ & $\begin{array}{c}\text { p-value } \\
\text { (within groups) }\end{array}$ \\
\hline Pre-treatment & $22.80 \pm 2.65$ & $23.20 \pm 2.14$ & 0.6531 \\
Post-treatment & $21.47 \pm 2.42$ & $23.07 \pm 2.05$ & 0.0606 \\
Improvement \% & $5.83 \%$ & $0.6 \%$ & 0.0001 \\
p-value (within groups) & 0.0001 & 0.3343 & \\
\hline
\end{tabular}

Table 4. The average test of Cognitive processing variable in both groups.

\begin{tabular}{cccc}
\hline Motor speed variable & $\begin{array}{c}\text { Study group } \\
\text { Mean } \pm \text { SD }\end{array}$ & $\begin{array}{c}\text { Control group } \\
\text { Mean } \pm \text { SD }\end{array}$ & $\begin{array}{c}\text { p-value } \\
\text { (within groups) }\end{array}$ \\
\hline Pre-treatment & $5.53 \pm 1.60$ & $6.07 \pm 1.58$ & 0.3657 \\
Post-treatment & $4.80 \pm 1.37$ & $5.80 \pm 1.47$ & 0.0647 \\
Improvement \% & $13.2 \%$ & $4.45 \%$ & 0.0043 \\
p-value (within groups) & 0.0001 & 0.0406 & \\
\hline
\end{tabular}

insignificant $(\mathrm{p}>0.05)$. Besides study group had a highly statistical progress in Motor speed variable post-treatment ( $p<0.05$ ), in contrast there was no statistical progress in the treatment group. The average progress of motor speed variable tended to be highly represented of the study group ( $5.53 \pm 1.60$ versus 4.80 $\pm 1.37 \mathrm{p}=0.0001)$ while insignificant result in the control group $(6.07 \pm 1.58$ versus $5.80 \pm 1.47 \mathrm{p}=0.0406)$. The proportion of progress of motor speed variable was $13.2 \%$ in the study group while it was $4.45 \%$ in control group.

\subsection{Changes in Cognitive Processing Variable}

Mean test scores and SD for the two groups are displayed in Table 5. The mean record of cognitive processing variable in both groups (assessed by decision making test) at baseline measurement (pre-treatment and post treatment) were insignificant $(p>0.05)$. Besides study group had a highly statistical progress in decision making variable post-treatment $(\mathrm{p}<0.05)$, in contrast there is no statistical progress in the treatment group. The average progress of decision making variable tended to be highly represented of the study group (6.27 \pm 1.49 versus $5.67 \pm 1.45 \mathrm{p}=0.0025)$ while insignificant result in the control group (5.40 \pm 1.06 versus $5.27 \pm 1.16 \mathrm{p}=0.1643)$. The proportion of progress of decision making variable was $9.569 \%$ in the study group while it was $2.4 \%$ in control group.

\subsection{Changes in Fine Motor Skill Variable}

Mean test scores and SD for the two groups are displayed in Table 6. The mean record of fine motor skill variable in both groups (assessed by grooved pegboard test) at baseline measurement (pre-treatment and post treatment) were insignificant $(\mathrm{p}>0.05)$. Besides study group had a highly statistical progress in 
Table 5. The average test of Cognitive processing variable in both groups.

\begin{tabular}{cccc}
\hline Decision making variable & $\begin{array}{c}\text { Study group } \\
\text { Mean } \pm \text { SD }\end{array}$ & $\begin{array}{c}\text { Control group } \\
\text { Mean } \pm \text { SD }\end{array}$ & $\begin{array}{c}\text { p-value } \\
\text { (within groups) }\end{array}$ \\
\hline Pre-treatment & $6.27 \pm 1.49$ & $5.40 \pm 1.06$ & 0.0762 \\
Post-treatment & $5.67 \pm 1.45$ & $5.27 \pm 1.16$ & 0.4111 \\
Improvement \% & $9.569 \%$ & $2.4 \%$ & 0.0433 \\
p-value (within groups) & 0.0025 & 0.1643 & \\
\hline
\end{tabular}

Table 6. The average test of efficiency of fine motor skills variable in both groups.

\begin{tabular}{cccc}
\hline $\begin{array}{c}\text { Fine motor skill } \\
\text { variable }\end{array}$ & $\begin{array}{c}\text { Study group } \\
\text { Mean } \pm \text { SD }\end{array}$ & $\begin{array}{c}\text { Control group } \\
\text { Mean } \pm \text { SD }\end{array}$ & $\begin{array}{c}\text { p-value } \\
\text { (within groups) }\end{array}$ \\
\hline Pre-treatment & $96.53 \pm 2.53$ & $96.80 \pm 3.41$ & 0.8095 \\
Post-treatment & $94.93 \pm 2.55$ & $96.67 \pm 3.37$ & 0.1236 \\
Improvement \% & 1.657 & $0.13 \%$ & 0.0001 \\
p-value (within groups) & 0.0001 & 0.1643 & \\
\hline
\end{tabular}

fine motor skill variable post-treatment $(\mathrm{p}<0.05)$, in contrast there is no statistical progress in the treatment group. The average progress of fine motor skill variable tended to be highly represented of the study group $(96.53 \pm 2.53$ versus $94.93 \pm 2.55 \mathrm{p}=0.0001)$ while insignificant result in the control group (96.80 \pm 3.41 versus $96.67 \pm 3.37 \mathrm{p}=0.1643)$. The proportion of progress of fine motor skill variable was $1.657 \%$ in the study group while it was $0.13 \%$ in control group.

\section{Discussion}

The sensory system plays an essential and vital role in skills development. ASD has an incoordination between the received feedback by the sensory system and the motor commands response by the higher centers [31]. The sensory system composed of two systems. The external one include the vision, smell, taste, hearing and tactile stimulation [32]. In addition to the internal one which include vestibular and somatosensory sensations [33]. This system filled in the gap between brain processing to feedback and different body parts for initiation and producing of movement [32] [34] [35] as in Figure 1.

Lowest fascial expressions with delayed eye contact were the main causes of delayed social skills [38]. Poor motor coordination and motor delay are the main causes of clumsiness and gait abnormalities [39]. The other motor impairments in ASD include reduced muscle tone due to undeveloped muscle and clumsy uncoordinated movement plus delaying in motor and posture activities plus perceptual motor integration functions [8] as in Figure 2.

Sensory systems retraining program via sensory integrating approach provided the CNS with the essential feedback inputs to correct the sensory processing problems. This will lead to enhancement of the motor planning which lead to improve the quality of activity of daily living and skills [40]. 


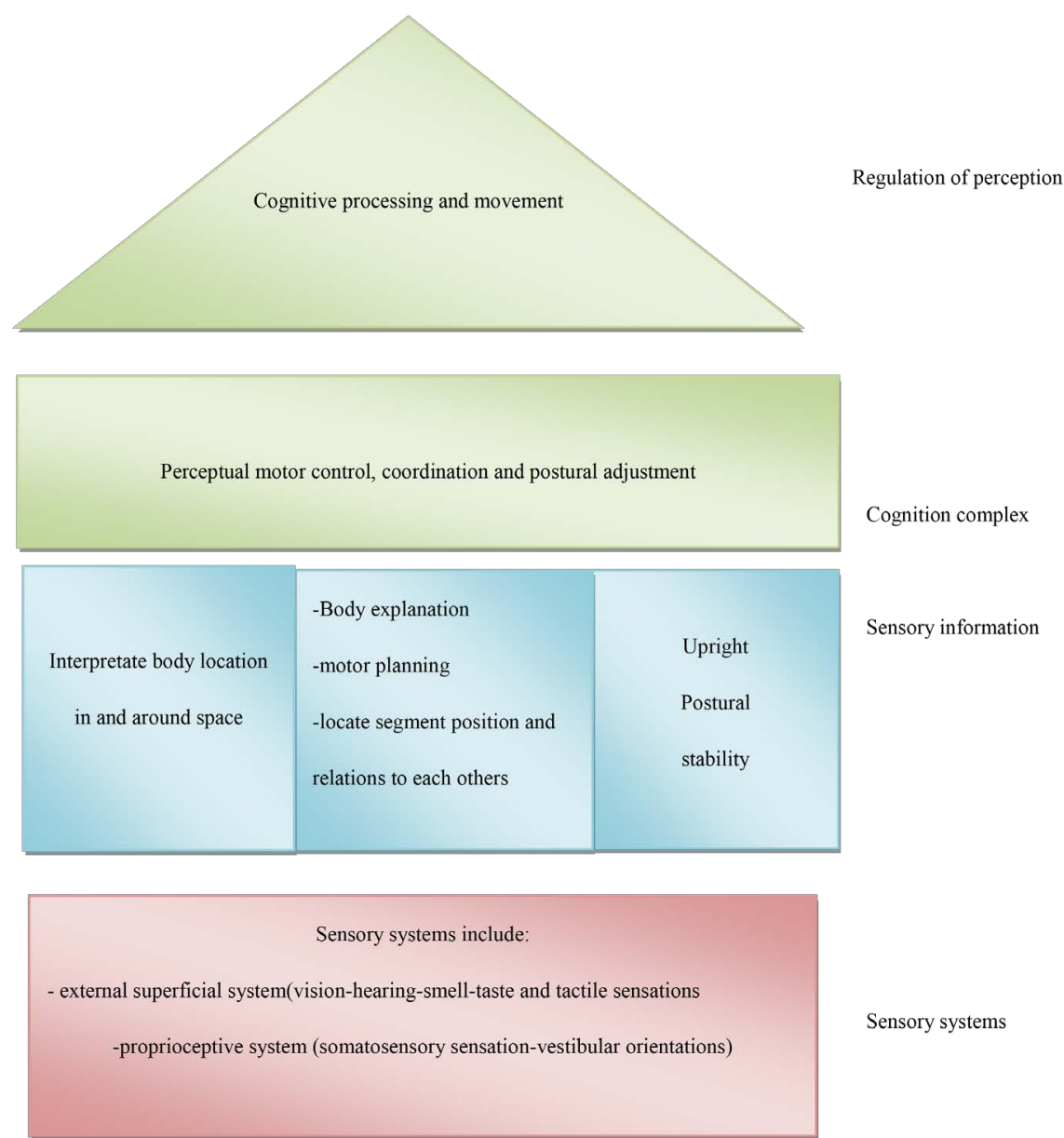

Figure 1. Sensory systems as a foundation of movment [36] [37].

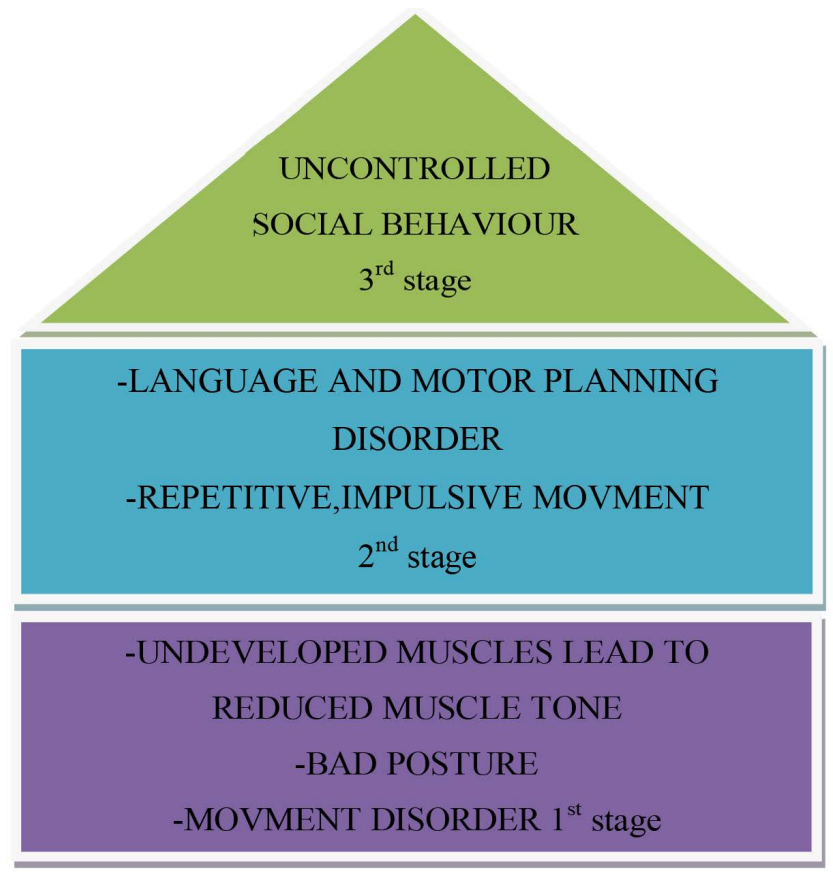

Figure 2. Stages of motor disorders in autism [45]. 
Sensory integration approach reorganize of the link between learning difficulties and impaired sensory processing [41]. The main problem which facing ASD is the incorrect interpretation of sensory processing which leaded to poor motor plan and abnormal motor behavior [42]. The sensory and motor abnormalities that present in autism include disorders in perception of sound, vision, smell, taste, tactile plus the proprioception sensation. These abnormalities are present in hyper and hypo responsiveness to sensory input [43]. These sensory abnormalities prevent acquisition of new skills which interfere with ADL activities, fine motor skills, social and communication interaction [16] [44].

The child will develop skills when tactile sense was properly perceived. Development of body awareness produced intentional movement. Children who suffered from impairment tactile sense had difficulty in learning new skills leading to delaying in gross and fine motor skills plus delaying in independent daily activities [25]. The autistic children suffered from motor impairment as slow walking, gait abnormality, short stride length, increase knee flexion and impaired reciprocal upper limbs movement [46].

The vestibular receptors are stimulated by movement (linear-rotation-change position) and gravity which played an essential role in each movement. Vestibular receptors concerning with gravity stimulation maintained the stance and movement situations to be able to produce sufficient movement without hazards. Autistic child has vestibular disorder in which there is sensory information from inner ear which wasn't sufficiently perceived by the brain in which there is inefficient integrating information to movement, gravity, balance and space leading to oversensitive or insensitive responses to movement or both of them. This will lead to delayed postural control, walking, collapse when sitting, clumsy uncoordinated movement, repeated fall down [22]. The motor deficits in ASD are: impaired vestibular control, delayed fine and gross motor skills [47], reduced ipsilateral activation of cerebellum during gross motor skills [48] [49]. And sensory integration dysfunction in cerebellum or basal ganglion produced abnormal gait and lacking postural control [50] [51] [52] as in Figure 2.

Motor, sensory and cognitive disorders present in ASD due to sensory integration dysfunction in cerebellum [53] [54]. Most of the ASD children suffering from abnormal gait in the form of toe gait due to tightness of tendoachilis and hamestring with weakness of plantar flexors and quadriceps produce limitation of dorsiflexion, knee extension and hip extension [46].

Delaying of fine motor skill and visual motor integration produce delaying in cognitive skills in ASD [55] [56]. Vestibular apparatus plays an essential role in acquisition of new skills via motor planning stimulation. In ASD the central nervous system cannot process the sensation concerning about balance and skills. So the children cannot learn a new skill [57] [58]. Proprioceptive sensation played a vital role in postural and motor control, motor planning, sensory awareness, learning of straight walking, upside down activity [25] [26] [27].

Proprioceptive sensation impairment occured in ASD leading to insufficient 
feedback needed for development gross and fine skills. The child cannot receive necessary information from the joints and muscles so there is failing in distinguishing between different movement and failing in modifying the body posture and balance in performing ADL activities [24].

Proprioceptive impairment leading to:

- Delaying in interpretation and perceptions of body position and movement.

- Delaying in fine and gross motor control and motor planning.

- Lack of body awareness and position.

- Difficulty in walking.

- Poor dealing with objects.

- Insufficient pressure on object.

- Difficulty in carrying heavy objects.

- Difficulty in getting dressed, buttoning and other ADL activities.

- Lack of postural balance [18] [24] as in Figure 3.

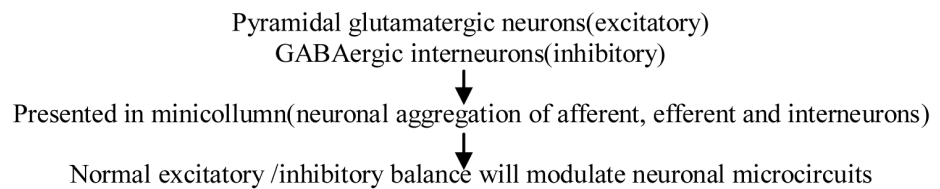

Absent of this mechanism in ASD [59] [60]
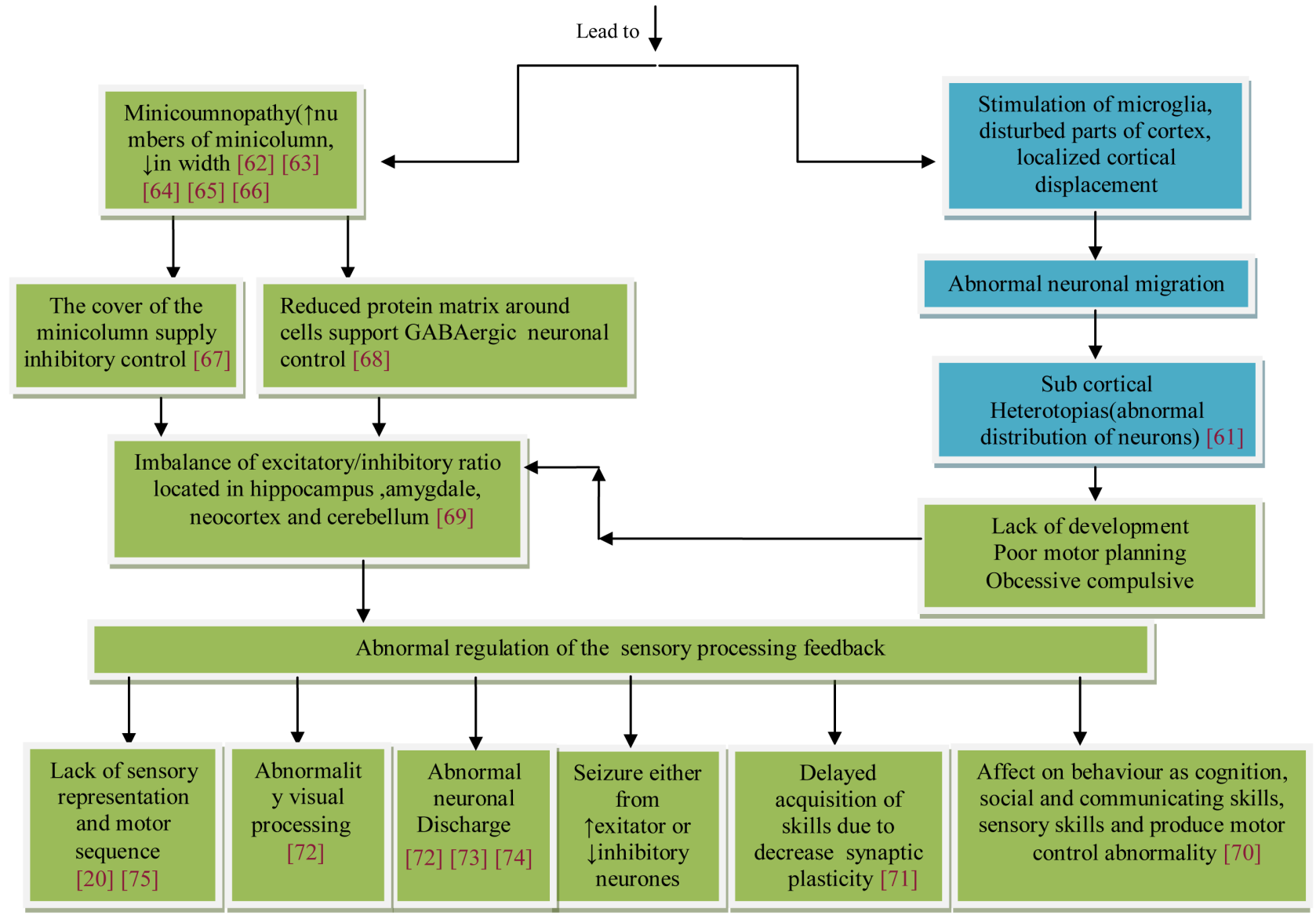

Figure 3. Underlying mechanisms of ASD physical, O.T. and behavioural problems. 


\section{Conclusion}

According to the outcomes of this study, it can be terminated that the sensory integration therapy approach plus static and intermittent inversion therapy techniques can be recommended in improvement constructional apraxia and cognitive processing abilities in autism spectrum disorder (ASD) children.

\section{Competing Interests}

There is no conflict of interest.

\section{Acknowledgements}

I am grateful to my professor Emam Elnegmy for his help and advices.

\section{References}

[1] Rolf, I.P. (2017) Kinesiolpogy Scientific Basic of Human Motion Active Soma Posture, Performance, Wellbeing. 8th Edition, 355.

[2] Dotto, L., et al. (1993) How Do You Go to the Bathroom in Space? The Astronauts: Canada's Voyageurs in Space. General Distribution Services Incorporate.

[3] Canale, S.T. and Beaty, J.H. (2007) Campbell's Operative Orthopaedics. 11st Edition, Vol. 4.

[4] Raut, A.A. and Bagde, S.T. (2014) Inversion Therapy \& Zero Gravity Concept: For All Back Pain Problems. IOSR Journal of Mechanical and Civil Engineering, 18-22.

[5] West, J., Otte, C., Geher, K., Johnson, J. and Mohr, D.C. (2004) Effects of Hatha Yoga and African Dance on Perceived Stress, Affect and Salivary Cortisol. Annals of Behavioral Medicine, 28, 114-118. https://doi.org/10.1207/s15324796abm2802_6

[6] Koffler, K. (2015) Director of Integrative Medicine. University of Northwestern, Saint Paul.

[7] Bigos, S., Bowyer, O., Braen, G., et al. (1994) Acute Low Back Problems in Adults: Clinical Practice Guideline, No. 14. Agency for Health Care Policy and Research, Public Health Service, US Department of Health and Human Services, Rockville.

[8] Jasmin, E., CouturE, M., Mckinley, P., Reid, G., Fombonne, E. and Gisel, E. (2009) Sensori-Motor and Daily Living Skills of Preschool Children with Autism Spectrum Disorders. Journal of Autism and Developmental Disorders, 39, 231-241. https://doi.org/10.1007/s10803-008-0617-z

[9] Dawson, G. and Watling, R. (2000) Interventions to Facilitate Auditory, Visual, and Motor Integration in Autism: A Review of the Evidence. Journal of Autism and Developmental Disorders, 30, 415-421.

[10] Bhat, A.N., Landa, R.J. and Cole-Galloway, J.C. (2011) Current Perspectives on Motor Functioning in Infants, Children, and Adults with Autism Spectrum Disorders. Physical Therapy, 91, 1116-1129. https://doi.org/10.2522/ptj.20100294

[11] Prasad, K.S., Gregson, B.A., Hargreaves, G., Byrnes, T., Winburn, P. and Mendelow, A.D. (2012) Inversion Therapy in Patients with Pure Single Level Lumbar Discogenic Disease: A Pilot Randomized Trial. Disability \& Rehabilitation, 34, 1473-1480.

[12] Onel, D., Tuzlaci, M., Sari, H. and Demir, K. (1989) Computed Tomographic Investigation of the Effect of Traction on Lumbar Disc Herniations. Spine, 14, 82-90. https://doi.org/10.1097/00007632-198901000-00017

[13] Krase, M., Refshauge, K.M., Dessen, M. and Boland, R. (2000) Lumbar Spine Trac- 
tion, Evaluation of Effects and Recommended Application for Treatment. Manual Therapy, 5, 72-81. https://doi.org/10.1054/math.2000.0235

[14] Kraus, S.L., Woerman, A. and Saunders, R. (1993) Evaluation, Treatment and Prevention of Musculoskeletal Disorders. University of Michigan, Ann Arbor.

[15] Tombaugh, T.N., et al. (2010) The Computerized Test of Information Processing (CTIP) Offers an Alternative to the PASAT for Assessing Cognitive Processing Speed in Individuals with Multiple Sclerosis. Cognitive and Behavioral Neurology, 23, 192-198. https://doi.org/10.1097/WNN.0b013e3181cc8bd4

[16] Case-Smith, J. and Bryan, T. (1999) The Effects of Occupational Therapy with Sensory Integration Emphasis on Preschool-Age Children with Autism. American Journal of Occupational Therapy, 53, 489-497. https://doi.org/10.5014/ajot.53.5.489

[17] Larson, J.C.G., Bastian, A.J., Donchin, O., Shadmehr, R. and Mostofsky, S.H. (2008) Acquisition of Internal Models of Motor Tasks in Children with Autism. Brain, 131, 2894-2903. https://doi.org/10.1093/brain/awn226

[18] Fazlioglu, Y. and Gunsen, M.O. (2011) Sensory Motor Development in Autism. In Mohammadi, M.R., Ed., A Comprehensive Book on Autism Spectrum Disorders, IntechOpen, Rijeka, 345-368.

[19] Dewey, D., Cantell, M. and Crawford, S.G. (2007) Motor and Gestural Performance in Children with Autism Spectrum Disorders, Developmental Coordination Disorder, and/or Attention Deficit Hyperactivity Disorder. Journal of the International Neuropsychological Society, 13, 246-256.

[20] Dowell, L.R., Mahone, E.M. and Mostofsky, S.H. (2009) Associations of Postural Knowledge and Basic Motor Skill with Dyspraxia in Autism: Implication for Abnormalities in Distributed Connectivity and Motor Learning. Neuropsychology, 23, 563-570. https://doi.org/10.1037/a0015640

[21] Dziuk, M.A., Texas, A., Larson, J.C.G., Apostu, A., Mahone, E.M., Denckla, M.B. and Mostofsky, S.H. (2007) Dyspraxia in Autism: Association with Motor, Social, and Communicative Deficits. Developmental Medicine \& Child Neurology, 49, 734-739. https://doi.org/10.1111/j.1469-8749.2007.00734.x

[22] Murphy, V. (2009) Effects of Sensory Integration on Motor Development in K-3 Students with Autism. M.Sc. Thesis, San Jose State University, San Jose, Unpublished.

[23] Einy, A.O., Lotan, M., Harel, Y., et al. (2013) Physical Therapy for Young Children Diagnosed with Autism Spectrum Disorders - Clinical Frameworks Model in an Israeli Setting. Frontiers in Pediatrics, 1, 19. https://doi.org/10.3389/fped.2013.00019

[24] Temel, F. (1992) Duyusal kaynastirma terapisinin ozurlu cocuklarda kullanilmasi. Cocuk norolojisi gunleri ozet kitabi, C-28, Istanbul.

[25] Bahr, D. (2001) Oral Motor Assessment and Treatment: Ages and Stages. Allyn \& Bacon, Boston.

[26] Kranowitz, C.S. (1998) The Out-of-Sync Child: Recognizing and Coping with Sensory Integration Dysfunction. Skylight Press, New York.

[27] Fisher, A.G. and Murray, E.A. (1991) Introduction to Sensory Integration Theory. In: Fisher, A.G., Murray, E.A., Bundy, A.C. and Sensory, F.A., Eds., Sensory Integration: Theory and Practice, Davis Company, Philadelphia, 3-24.

[28] Kayihan, H. (1989) Hemipleji'de iş ve uğraşi tedavisi. Hacettepe Universitesi Fizik Tedavi ve Rehabilitasyon Yayinlari, Ankara, 118.

[29] Royeen, C.B. and Lane, S.J. (1991) Tactile Processing and Sensory Defensiveness. In: 
Fisher, A.G., Murray, E.A., Bundy, A.C. and Sensory, F.A., Eds., Sensory Integration: Theory and Practice, Davis Company, Philadelphia, 108-133.

[30] Subramanian, S.S. (2015) Case Study Report on a Parkinson's Disease Patient with Inversion Therapy Using Physioball and Inversion Based Yoga Postures. IOSR Journal of Pharmacy and Biological Sciences, 10, 73-76.

http://www.iosrjournals.org/

[31] Marco, E.J., et al. (2012) Children with Autism Show Reduced Somatosensory Response: An MEG Study. Autism Research, 5, 340-351. https://doi.org/10.1002/aur.1247

[32] Dunn, W., Saiter, J. and Rinner, L. (2002) Asperger Syndrome and Sensory Processing: A Conceptual Model and Guidance for Intervention Planning. Focus on Autism and Other Developmental Disabilities, 17, 172-185. https://doi.org/10.1177/10883576020170030701

[33] Damann, N., Voets, T. and Nilus, B. (2008) TRPs in Our Senses. Current Biology, 18, R880-R889. https://doi.org/10.1016/j.cub.2008.07.063

[34] Glomstad, J. (2004) Studying SPD in a Primate Model, Advance for Occupational Therapy Practitioners. 3-33.

[35] Shumay-Cook, A. and Woollacott, M.H. (2007) Motor Control: Translating Research into Clinical Practice. 3rd Edition, Lippincott Williams \& Wilkins, Baltimore.

[36] Auxter, D., et al. (2010) Principles and Methods of Adapted Physical Education and Recreation. 11st Edition, McGraw-Hill Education, Boston.

[37] Haywood, K.M. and Getchell, N. (2009) Life Span Motor Development. 5th Edition, Human Kinetics, Champaign.

[38] Lord, C., Pickles, A. and Mclennan, J. (1997) Diagnosing Autism: Analyses of Data from the Autism Diagnostic Interview. Journal of Autism and Developmental Disorders, 27, 501-517. https://doi.org/10.1023/A:1025873925661

[39] Jansiewicz, E.M., et al. (2006) Motor Signs Distinguish Children with High Functioning Autism and Asperger's Syndrome from Controls. Journal of Autism and Developmental Disorders, 36, 613-621. https://doi.org/10.1007/s10803-006-0109-y

[40] Lane, S.J. and Schaaf, R.C. (2010) Examining the Neuroscience Evidence for Sensory-Driven Neuroplasticity: Implications for Sensory-Based Occupational Therapy for Children and Adolescents. American Journal of Occupational Therapy, 64, 375-390. https://doi.org/10.5014/ajot.2010.09069

[41] Dunkerley, E., Tickl-Degnen L. and Coster, W.J. (1997) Therapist-Child Interaction in the Middle Minutes of Sensory Integration Treatment. American Journal of Occupational Therapy, 51, 799-805. https://doi.org/10.5014/ajot.51.10.799

[42] Baranek, G. (2002) Efficacy of Sensory and Motor Interventions for Children with Autism. Journal of Autism and Developmental Disorders, 32, 397-422. https://doi.org/10.1023/A:1020541906063

[43] Attwood, T. (1993) Unusual Behaviors Associated with Autism. Health Visitor, 66, 402-403.

[44] Fazlioglu, Y. and Baran, G. (2008) A Sensory Integration Therapy Program on Sensory Problems for Children with Autism. Perceptual and Motor Skills, 106, 415-422. https://doi.org/10.2466/pms.106.2.415-422

[45] Mari, M., et al. (2003) The Reach-to-Grasp Movement in Children with Autism Spectrum Disorder. Philosophical Transactions of the Royal Society. Biological Sciences, 358, 393-403. https://doi.org/10.1098/rstb.2002.1205 
[46] Vilensky, J.A., Damasio, A.R. and Maurer, R.G. (1981) Gait Disturbance in Patients with autistic Behavior: A Preliminary Study. Archives of Neurology, 38, 646-649. https://doi.org/10.1001/archneur.1981.00510100074013

[47] Freitag, C.M., et al. (2007) Quantitative Assessment of Neuromotor Function in Adolescents with High Functioning Autism and Asperger Syndrome. Journal of Autism and Developmental Disorders, 37, 948-959. https://doi.org/10.1007/s10803-006-0235-6

[48] Mostofsky, S.H. (2009) Decreased Connectivity and Cerebellar Activity in Autism during Motor Task Performance. Brain, 132, 2413-2425, https://doi.org/10.1093/brain/awp088

[49] Allen, G. and Courchesne, E. (2003) Differential Effects of Developmental Cerebellar Abnormality on Cognitive and Motor Functions in the Cerebellum: An fMRI Study of Autism. The American Journal of Psychiatry, 160, 262-273. https://doi.org/10.1176/appi.ajp.160.2.262

[50] Minshew, N.J., et al. (2004) Underdevelopment of the Postural Control System in Autism. Neurology, 63, 2056-2061. https://doi.org/10.1212/01.WNL.0000145771.98657.62

[51] Rinehart, N.J., et al. (2006) Gait Function in High-Functioning Autism and Asperger's Disorder: Evidence for Basal-Ganglia and Cerebellar Involvement? European Child and Adolescent Psychiatry, 15, 256-264. https://doi.org/10.1007/s00787-006-0530-y

[52] Fournier, K.A. (2010) Motor Coordination in Autism Spectrum Disorders: A Synthesis and Meta-Analysis. Journal of Autism and Developmental Disorders, 40, 1227-1240. https://doi.org/10.1007/s10803-010-0981-3

[53] Schmahmann, J.D. (1997) The Cerebellum and Cognition. Academic Press, San Diego.

[54] Schmahmann, J.D., Rosene, D.L. and Pandya, D.N. (2004) Motor Projections to the Basis Pontis in Rhesus Monkey. Journal of Comparative Neurology, 478, 248-268. https://doi.org/10.1002/cne.20286

[55] Green, D., Chaman, T., Pickles, A., et al. (2009) Impairment in Movement Skills of Children with Autistic Spectrum Disorder. Developmental Medicine and Child Neurology, 51, 311-316

[56] David, F.G., Baranek, G.T., Weisen, C., et al. (2012) Coordination of Precision Grip in 2 - 6 Years with Autistic Spectrum Disorder Compared to Children Developing Typically and Children with Developmental Disabilities. Frontiers in Integrative Neuroscience, 6, 122.

[57] Reiss, S. and Havercamp, S.M. (1997) Sensivity Theory and Mental Retardation: Why Functional Analysis Is Not Enough. American Journal of Mental Retardation, 101, 553-566.

[58] Rogers, S.J., Hepburn, S.L., Stackhause, T. and Wehner, E. (2003) Imitation Performance in Toddlers with Autism and Those with Other Developmental Disorders. Journal of Child Psychology Psychiatry, 44, 763-781. https://doi.org/10.1111/1469-7610.00162

[59] Casanova, M.F. (2007) The Neuropathology of Autism. Brain Pathology, 17, 422-433. https://doi.org/10.1111/j.1750-3639.2007.00100.x

[60] Opris, I. and Casanova, M.F. (2014) Prefrontal Cortical Minicolumn: From Executive Control to Disrupted Cognitive Processing. Brain, 137, 1863-1875. https://doi.org/10.1093/brain/awt359

[61] Casanova, M.F., El-Baz, E.S., Kamat, S.S., Dombroski, B.A., Khalifa, F., Elnakib, A., et al. (2013) Focal Cortical Dysplasias in Autism Spectrum Disorders. Acta Neuro- 
pathologica Communications, 1, 67. https://doi.org/10.1186/2051-5960-1-67

[62] Casanova, M.F. (2006) Neuropathological and Genetic Findings in Autism: The Significance of a Putative Minicolumnopathy. Neuroscientist, 12, 435-441. https://doi.org/10.1177/1073858406290375

[63] Casanova, M.F., Buxhoeveden, D.P. and Brown, C. (2002) Clinical and Macroscopic Correlates of Minicolumnar Pathology in Autism. Journal of Child Neurology, 17, 692-695. https://doi.org/10.1177/088307380201700908

[64] Casanova, M.F., Buxhoeveden, D., Switala, A. and Roy, E. (2003) Rett Syndrome as a Minicolumnopathy. Clinical Neuropathology, 22, 163-168.

[65] Casanova, M.F., Buxhoeveden, D. and Gomez, J. (2003) Disruption in the Inhibitory Architecture of the Cell Minicolumn: Implications for Autism. Neuroscientist, 9, 496-507. https://doi.org/10.1177/1073858403253552

[66] Casanova, M.F., El-Baz, A., Vanbogaert, A., Narahari, P. and Switala, A. (2010) A Topographic Study of Minicolumnar Core Width by Lamina Comparison between Autistic Subjects and Controls: Possible Minicolumnar Disruption due to an Anatomical Element In-Common to Multiple Laminae. Brain Pathology, 20, 451-458. https://doi.org/10.1111/j.1750-3639.2009.00319.x

[67] Casanova, M.F. (2008) The Minicolumnopathy of Autism: A Link between Migraine and Gastrointestinal Symptoms. Medical Hypotheses, 70, 73-80. https://doi.org/10.1016/j.mehy.2007.04.025

[68] Folsom, T.D. and Fatemi, S.H. (2013) The Involvement of Reelin in Neurodevelopmental Disorders. Neuropharmacology, 68, 122-135. https://doi.org/10.1016/j.neuropharm.2012.08.015

[69] Rubenstein, J.L.R. and Merzenich, M.M. (2003) Model of Autism: Increased Ratio of Excitation/Inhibition in Key Neural Systems. Genes, Brain and Behavior, 2, 255-267. https://doi.org/10.1034/j.1601-183X.2003.00037.x

[70] Yizhar, O., Fenno, L.E., Prigge, M., Schneider, F., Davidson, T.J., O’Shea, D.J., et al. (2011) Neocortical Excitation/Inhibition Balance in information Processing and Social Dysfunction. Nature, 477, 171-178. https://doi.org/10.1038/nature10360

[71] Oberman, L., Ifert-Miller, F., Najib, U., Bashir, S., Woolacott, I., Gonzalez-Heydrich, J., et al. (2010) Transcranial Magnetic Stimulation Provides Means to Assess Cortical Plasticity and Excitability in Humans with Fragile X Syndrome and Autism Spectrum Disorder. Frontiers in Synaptic Neuroscience, 2, 26.

https://doi.org/10.3389/fnsyn.2010.00026

[72] Grice, S.J., Spratling, M.W., Karmiloff-Smith, A., Halit, H., Csibra, G., de Haan, M., et al. (2001) Disordered Visual Processing and Oscillatory Brain Activity in Autism and Williams Syndrome. Neuroreport, 12, 2697-2700.

https://doi.org/10.1097/00001756-200108280-00021

[73] Orekhova, E.V., Stroganova, T.A., Prokofyev, A.O., Nygren, G., Gillberg, C. and Elam, N. (2008) Sensory Gating in Young Children with Autism: Relation to Age, IQ and EEG Gamma Oscillations. Neuroscience Letters, 434, 218-223. https://doi.org/10.1016/j.neulet.2008.01.066

[74] Gandal, M.J., Edgar, J.C., Erlichman, R.S., Mehta, M., Roberts, T.P. and Siegel, S.J. (2010) Validating $\gamma$ Oscillations and Delayed Auditory Responses as Translational Biomarkers of Autism. Biological Psychiatry, 68, 1100-1106. https://doi.org/10.1016/j.biopsych.2010.09.031

[75] Mostofsky, S.H., Dubey, P., Jerath, V.K., Jansiewitz, E.M., Goldberg, M.C. and Denkla, M.B. (2006) Developmental Dyspraxia Is Not Limited to Imitation in Children with Autism Spectrum Disorders. Journal of the International Neuropsychological Society, 12, 314-326. https://doi.org/10.1017/S1355617706060437 